\title{
A new rationale for preservation of the mandibular third molar in orthognathic patients with missing molars
}

\author{
Un-Bong Baik ${ }^{1, \star}$, Yoon-Ji Kim²,*, Hwa-Sung Chae ${ }^{3}$, Je-Uk Park', Stefania Julian ${ }^{5}$, Junji Sugawara ${ }^{6}$, Ui-Lyong Lee ${ }^{7}$ \\ ${ }^{1}$ Private Practice, Seoul, ${ }^{2}$ Department of Orthodontics, Korea University Anam Hospital, Seoul, \\ ${ }^{3}$ Department of Orthodontics, Institute of Oral Health Science, Ajou University School of Medicine, Suwon, \\ ${ }^{4}$ Department of Oral and Maxillofacial Surgery, Seoul St. Mary's Hospital, Catholic University of Korea, Seoul, Korea, \\ ${ }^{5}$ Orthodontics and Maxillary Orthopedics, University of Salvador, Buenos Aires, Argentina, \\ ${ }^{6}$ SAS Orthodontic Centre, Ichiban-Cho Dental Clinic, Sendai, Japan, \\ ${ }^{7}$ Department of Oral and Maxillofacial Surgery, Dental Center, Chung-Ang University Hospital, Seoul, Korea
}

\begin{abstract}
J Korean Assoc Oral Maxillofac Surg 2022;48:63-67)
Controversies exist regarding the need for prophylactic extraction of mandibular third molars in patients who plan to undergo orthognathic surgery. An 18-year-old male patient was diagnosed with mandibular prognathism and maxillary retrognathism with mild facial asymmetry. He had a severely damaged mandibular first molar and a horizontally impacted third molar. After extraction of the first molar, the second molar was protracted into the first molar space, and the third molar erupted into the posterior line of occlusion. The orthognathic surgery involved clockwise rotation of the maxillomandibular complex as well as angle shaving and chin border trimming. Patients who are missing or have damaged mandibular molars should be monitored for eruption of third molars to replace the missing posterior tooth regardless of the timing of orthognathic surgery.
\end{abstract}

Key words: Orthodontics, Orthognathic surgery, Sagittal split ramus osteotomy, Temporary anchorage device, Third molar [paper submitted 2020. 3. 31 / revised 2020. 4. 13 / accepted 2020. 4. 16]

\section{Introduction}

In patients with mandibular prognathism who are scheduled to undergo mandibular setback orthognathic surgery, it often is necessary to extract impacted third molars. When a third molar is located on the bone cutting line, bone segments can fracture inadvertently, and incomplete soft tissue coverage can interfere with wound healing and increase the risk of infection. Furthermore, even when intraoral vertical ramus osteotomy is performed, the third molar might not be located along the bone cutting line; when the mandible is set back, third molars can be buried by the soft tissues of the

\section{Ui-Lyong Lee}

Department of Oral and Maxillofacial Surgery, Dental Center, Chung-Ang University Hospital, 102 Heukseok-ro, Dongjak-gu, Seoul 06973, Korea TEL: +82-2-6299-2875

E-mail: davidjoy76@gmail.com

ORCID: https://orcid.org/0000-0002-0080-0169

*These authors contributed equally to this work as first authors.

(c) This is an open-access article distributed under the terms of the Creative Commons Attribution Non-Commercial License (http://creativecommons.org/ licenses/by-nc/4.0/), which permits unrestricted non-commercial use, distribution, and reproduction in any medium, provided the original work is properly cited.

Copyright (C) 2022 The Korean Association of Oral and Maxillofacial Surgeons. retromolar pad, increasing the possibility of inflammation. If postoperative infection is present while the patient undergoes intermaxillary fixation, it can be difficult to open the mouth, which complicates treatment.

Therefore, previous investigators have suggested that the third molars should be removed six months or more before a bilateral sagittal split ${ }^{1-4}$. However, recent studies have revealed that side effects (such as nerve damage and unfavorable fractures) are not increased in cases where third molars are extracted during orthognathic surgery ${ }^{5-8}$.

The mandibular first molar is one of the most commonly extracted teeth in the dentition, most often due to severe caries or periodontitis ${ }^{9,10}$. Because of technical advances in clinical orthodontics, such as temporary anchorage devices (TADs), second molars can be protracted, resulting in spontaneous eruption of impacted third molars. In the past, third molar protraction was performed only when the second molar was missing or extracted due to the proximity of the two teeth. However, many authors have reported that the second molars can be protracted in cases of damaged or missing first molars $^{11-16}$. 
If third molars are removed in orthognathic surgery patients whose first molar is damaged or missing, the space they leave behind should be filled by a dental implant. Therefore, if a horizontally impacted third molar can be erupted orthodontically via second molar protraction in patients who have damaged or missing mandibular first molars, the present protocol of prophylactic extraction of impacted third molars in orthognathic patients might need to be changed.

In this case report, we present a patient with a prognathic mandible and severely damaged first molar who underwent orthognathic surgery along with eruption of a horizontally impacted third molar that was prompted by lower second molar protraction.

\section{Case Report}

An 18-year-old male patient presented with a chief complaint of crowding and mandibular prognathism; he requested surgery to correct a protruded chin. He was diagnosed with Class III skeletal malocclusion, maxillary retrognathism, mandibular prognathism, and mild asymmetry. There were no transverse discrepancies. The right mandibular first molar was damaged severely by cavities, and the right mandibular third molar was impacted horizontally.(Fig. 1)

As a preoperative orthodontic treatment, extraction of the lower right first molar and protraction of the second molar were planned after leveling and alignment. Spontaneous eruption of the mandibular third molar into the second molar space was expected. For orthognathic surgery, clockwise rotation of the maxillomandibular complex as well as angle shaving and chin border trimming were planned. Extraction of the mandibular first molar followed by dental implantation is a common treatment option. Such an approach shortens and simplifies the treatment.

In the present case, the right mandibular first molar was extracted first, and the lower molars were aligned. After that, TADs were placed mesial to the space left by the extracted lower first molar, and second molar protraction began. In six months, the second molar was protracted considerably,

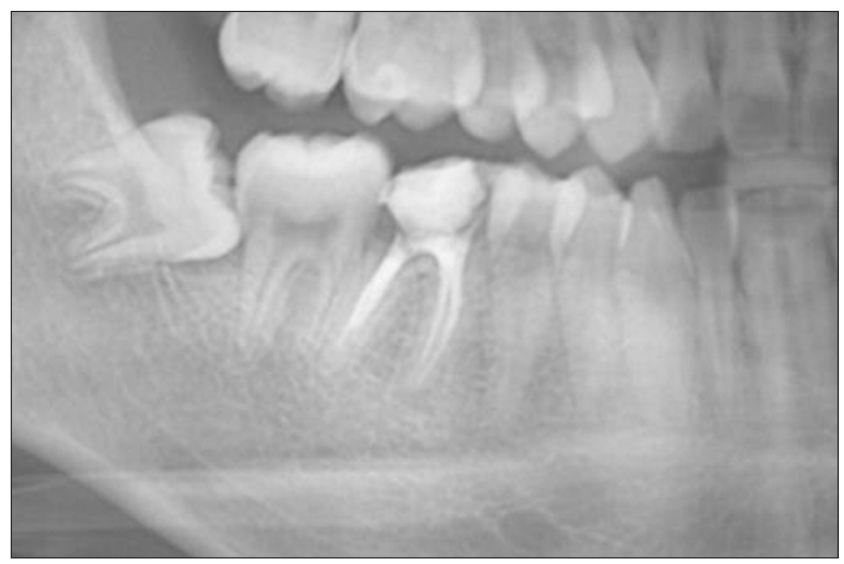

Fig. 1. Initial panoramic radiograph.

Un-Bong Baik et al: A new rationale for preservation of the mandibular third molar in orthognathic patients with missing molars. J Korean Assoc Oral Maxillofac Surg 2022

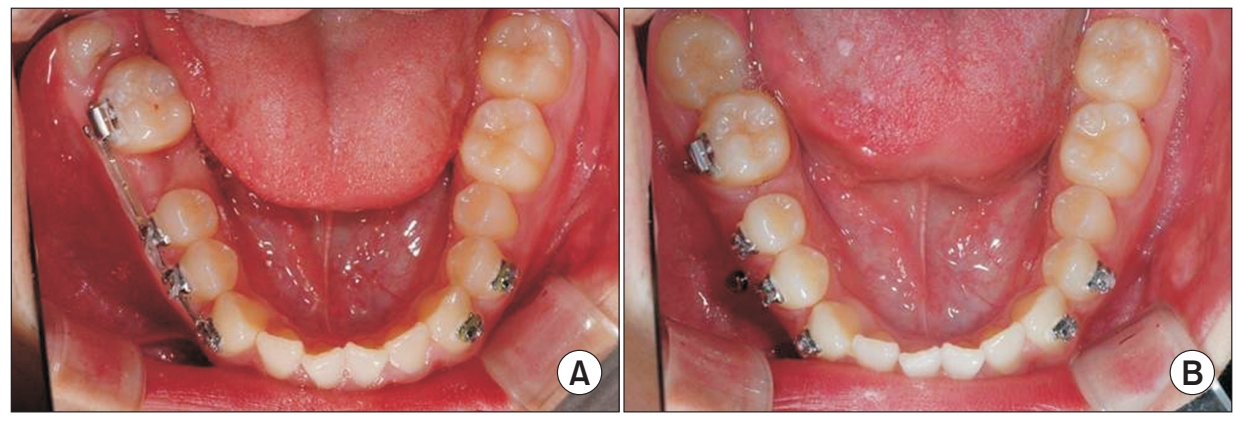

B.

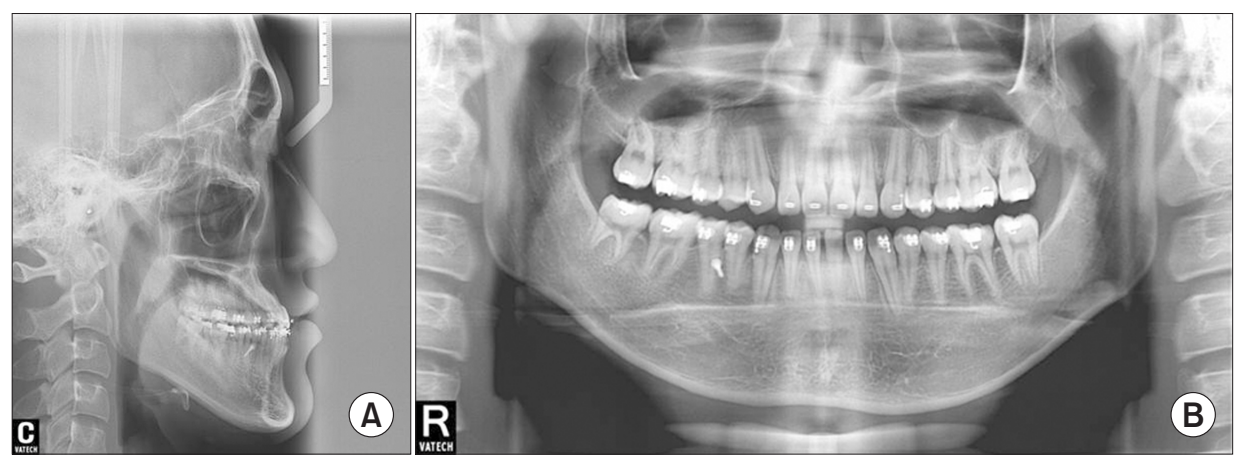

Fig. 3. A. Preoperative lateral cephalogram. B. Preoperative panoramic radiograph.

Un-Bong Baik et al: A new rationale for preservation of the mandibular third molar in orthognathic patients with missing molars. J Korean Assoc Oral Maxillofac Surg 2022 
and the third molar had erupted.(Fig. 2) These achievements allowed completion of preoperative orthodontics.(Fig. 3, 4) A maxillary Le Fort I osteotomy (4-mm posterior impaction of the posterior nasal spine based on the incisal edge), a mandibular sagittal split ramus osteotomy setback, and angle shaving were performed. After the surgery, postoperative orthodontic treatment was performed. Debonding was carried out after finishing and detailing. After treatment, the protruded chin, which was the patient's chief complaint, was corrected; in addition, the depression in the paranasal area and the chin border asymmetry were improved. Root parallelism was achieved throughout the whole dentition, including the second and third molars, and was confirmed on a panoramic radiograph.(Fig. 5) Imaging at two months postoperative showed no relapse of space. For retention, good occlusion is superior to any mechanical device. Therefore, no special retaining devices should be required for the protracted molars.

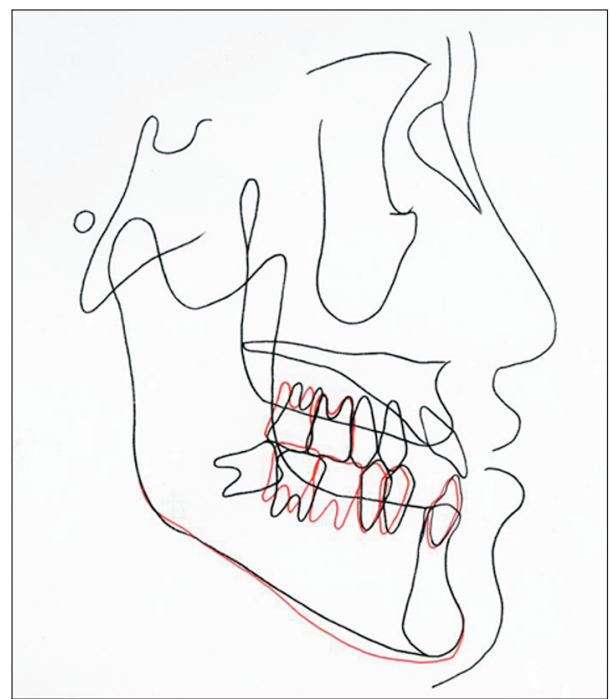

Fig. 4. Superimposition of the initial and preoperative cephalograms.

Un-Bong Baik et al: A new rationale for preservation of the mandibular third molar in orthognathic patients with missing molars. J Korean Assoc Oral Maxillofac Surg 2022

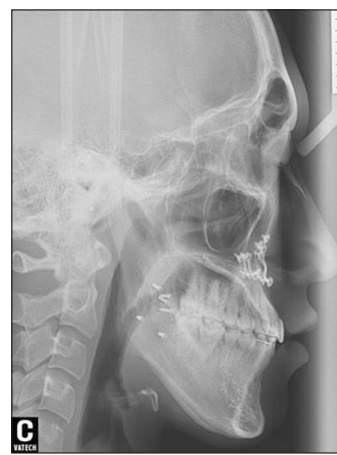

(A)
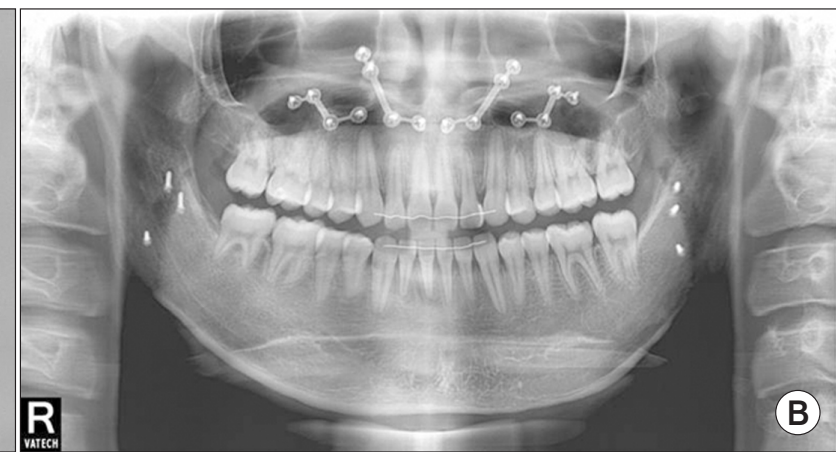

Fig. 5. A. Final lateral cephalogram. B. Final panoramic radiograph.

Un-Bong Baik et al: A new rationale for preservation of the mandibular third molar in orthognathic patients with missing molars. J Korean Assoc Oral Maxillofac Surg 2022

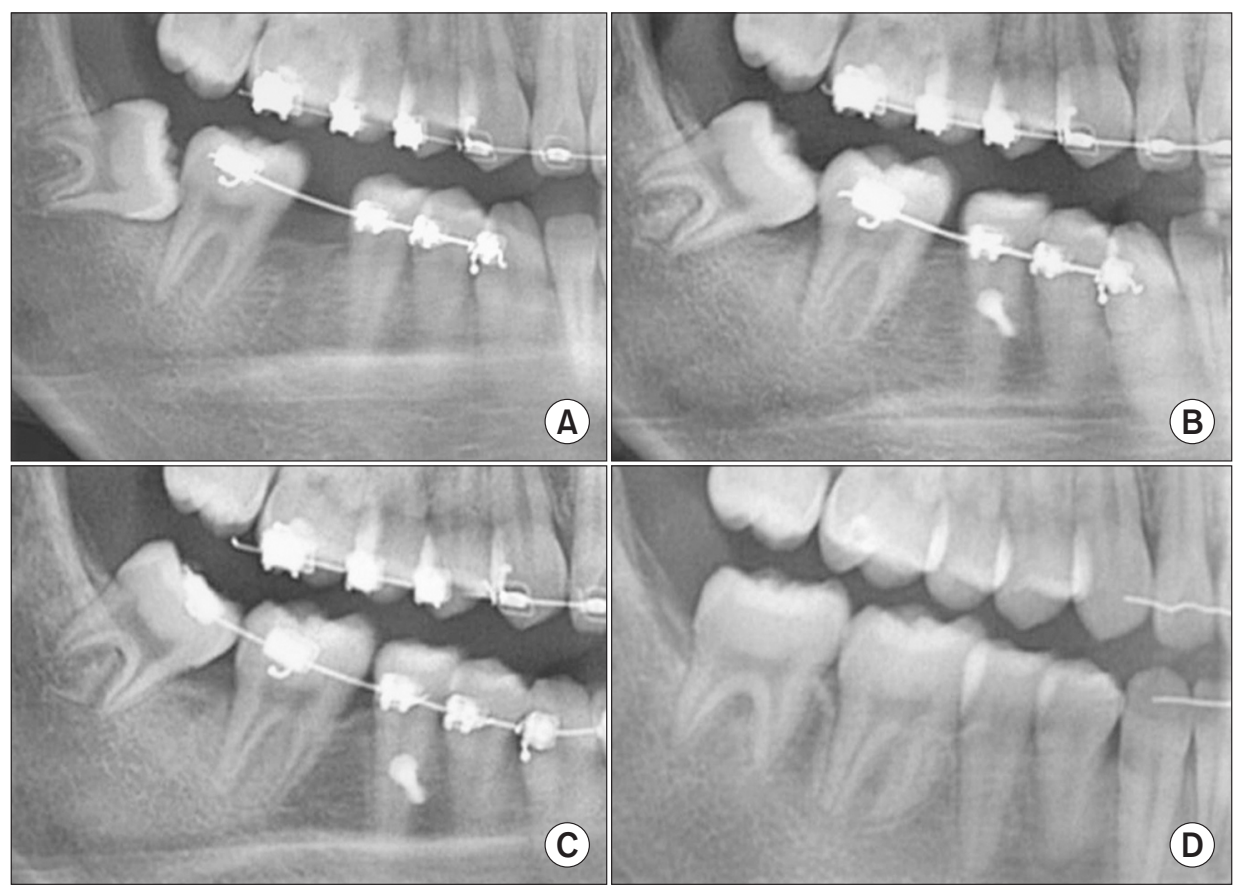

Fig. 6. Serial radiographs. A. Initial. B, C. During treatment. D. One year after treatment.

Un-Bong Baik et al: A new rationale for preservation of the mandibular third molar in orthognathic patients with missing molars. J Korean Assoc Oral Maxillofac Surg 2022 
The damaged right mandibular first molar tooth was extracted, and the space it left behind was occupied by the right mandibular second molar. In turn, the impacted right mandibular third molar filled the space previously occupied by the right mandibular second molar.(Fig. 6)

\section{Discussion}

The gold standard treatment for impacted third molars in patients scheduled to undergo mandibular setback surgery is extraction of the impacted third molars several months before surgery. However, this case report showed that preoperative orthodontic treatment can be used to align the third molar into occlusion after the second molar is protracted into the space left by the missing first molar. When the second molar is missing instead of the first, treatment becomes much easier because there is no need to protract the second molar; all that is necessary is eruption of the third molar.

Since the development of anchorage devices (such as orthodontic mini-screws and mini-plates), the range of orthodontic tooth movement has increased, and many missing teeth can be replaced orthodontically by the third molars. Recently, a "surgery first" approach has been introduced for this procedure where postoperative orthodontic treatment is performed after orthognathic surgery, even if the occlusion is not set. However, in patients with a damaged first molar or a horizontally impacted third molar who are to undergo molar protraction and eruption of the third molar, the surgery-first approach is not feasible. Although it is not necessary to close the extraction space and ensure complete alignment of the third molar, surgery should be delayed until the third molar is positioned away from the bone cutting line.

The most important problem commonly encountered when closing large defect spaces is mesial tilting of the adjacent tooth. Thus, it is important to protract the second molar by applying an orthodontic force vector that passes close to the center of rotation of the tooth ${ }^{3}$, which is often the root furcation. In the present case, we protracted the second molar in a parallel direction without mesial tilting.(Fig. 6) Possible side effects of this treatment include posterior molar extrusion, which can cause the mandible to rotate clockwise. This phenomenon was observed in the present case; however, the effect was minimized by controlling the force mechanics.(Fig. 4)

Spontaneous eruption of an impacted third molar is predictable when an available space is created by successful second molar protraction. Indeed, previous studies have shown that the impacted third molar erupts spontaneously to some extent when the second molar is protracted ${ }^{1}$. Baik et al. ${ }^{11,13}$ reported a case of a severely and completely horizontally impacted third molar being rotated into complete occlusion after second molar protraction into the missing first molar space.

The advantages of aligning the impacted third molar into the missing molar space are as follows: 1) prevention of pericoronitis of the third molars as they are erupted into occlusion, 2) elimination of dental implants or other prosthetic treatments, 3) restoration of the natural tooth and the advantages of a natural tooth, such as proprioception, and 4) no need to extract third molars.

In surgical treatment of dentofacial anomalies, the surgeryfirst approach is increasing in popularity due to its advantages, such as early functional restoration and efficient postsurgical orthodontics ${ }^{17-20}$. In these cases, presurgical extraction of third molars is not feasible, and orthodontic closure of the missing molar space and eruption of the third molar are not possible before surgery. However, a consensus has not yet been reached regarding presurgical extraction of third molars before orthognathic surgery ${ }^{5,7,8}$. Baek et al. ${ }^{18}$ reported successful treatment using a surgery-first approach without extracting the impacted third molars.

According to the currently available literature on management of third molars in orthognathic surgery, not all patients scheduled for orthognathic surgery should undergo prophylactic extraction of third molars. In addition, patients who are missing mandibular molars should be considered for eruption of third molars to replace the missing posterior tooth regardless of the timing of orthognathic surgery.

\section{ORCID}

\author{
Un-Bong Baik, https://orcid.org/0000-0002-9038-9229 \\ Yoon-Ji Kim, https://orcid.org/0000-0002-7030-569X \\ Hwa-Sung Chae, https://orcid.org/0000-0002-7738-2532 \\ Je-Uk Park, https://orcid.org/0000-0002-9704-5402 \\ Stefania Julian, https://orcid.org/0000-0003-1392-0992 \\ Junji Sugawara, https://orcid.org/0000-0003-3701-9031 \\ Ui-Lyong Lee, https://orcid.org/0000-0002-0080-0169
}

\section{Authors' Contributions}

U.B.B. and Y.J.K. participated in data collection and wrote the manuscript. H.S.C., J.U.P., S.J., and J.S. participated in the study design. U.L.L. participated in the study design and coordination and helped to draft the manuscript. All authors 
read and approved the final manuscript.

\section{Conflict of Interest}

No potential conflict of interest relevant to this article was reported.

\section{References}

1. Colelia G, Giudice A. The timing of third molar removal in patients undergoing a bilateral sagittal split osteotomy. J Oral Maxillofac Surg 2003;61:975. https://doi.org/10.1016/s0278-2391(03)00505-6

2. Mehra P, Castro V, Freitas RZ, Wolford LM. Complications of the mandibular sagittal split ramus osteotomy associated with the presence or absence of third molars. J Oral Maxillofac Surg 2001;59:854-8; discussion 859. https://doi.org/10.1053/ joms.2001.25013

3. Reyneke JP, Tsakiris P, Becker P. Age as a factor in the complication rate after removal of unerupted/impacted third molars at the time of mandibular sagittal split osteotomy. J Oral Maxillofac Surg 2002;60:654-9. https://doi.org/10.1053/joms.2002.33114

4. Van Sickels JE, Jeter TS, Theriot BA. Management of an unfavorable lingual fracture during a sagittal split osteotomy. J Oral Maxillofac Surg 1985;43:808-9. https://doi.org/10.1016/02782391(85)90341-6

5. Camargo IB, Van Sickels JE, Curtis WJ. Simultaneous removal of third molars during a sagittal split does not increase the incidence of bad splits in patients aged 30 years or older. J Oral Maxillofac Surg 2015;73:1350-9. https://doi.org/10.1016/j.joms.2015.01.023

6. Doucet JC, Morrison AD, Davis BR, Robertson CG, Goodday R, Precious DS. Concomitant removal of mandibular third molars during sagittal split osteotomy minimizes neurosensory dysfunction. J Oral Maxillofac Surg 2012;70:2153-63. https://doi.org/10.1016/ j.joms.2011.08.029

7. Schwartz HC. Simultaneous removal of third molars during sagittal split osteotomies: the case against. J Oral Maxillofac Surg 2004; 62:1147-9. https://doi.org/10.1016/j.joms.2004.04.015

8. Steinbacher DM, Kontaxis KL. Does simultaneous third molar extraction increase intraoperative and perioperative complications in orthognathic surgery? J Craniofac Surg 2016;27:923-6. https://doi. org/10.1097/SCS.0000000000002648

9. McCaul LK, Jenkins WM, Kay EJ. The reasons for the extraction of various tooth types in Scotland: a 15-year follow up. J Dent 2001;29:401-7. https://doi.org/10.1016/s0300-5712(01)00036-7

10. Sayegh A, Hilow H, Bedi R. Pattern of tooth loss in recipients of free dental treatment at the University Hospital of Amman, Jordan. J Oral Rehabil 2004;31:124-30. https://doi.org/10.1046/j.0305- 182x.2003.01229.x

11. Baik UB, Kook YA, Bayome M, Park JU, Park JH. Vertical eruption patterns of impacted mandibular third molars after the mesialization of second molars using miniscrews. Angle Orthod 2016; 86:565-70. https://doi.org/10.2319/061415-399.1

12. Kyung SH, Choi JH, Park YC. Miniscrew anchorage used to protract lower second molars into first molar extraction sites. J Clin Orthod 2003;37:575-9.

13. Baik UB, Chun YS, Jung MH, Sugawara J. Protraction of mandibular second and third molars into missing first molar spaces for a patient with an anterior open bite and anterior spacing. Am J Orthod Dentofacial Orthop 2012;141:783-95. https://doi.org/10.1016/ j.ajodo.2010.07.031

14. Nagaraj K, Upadhyay M, Yadav S. Titanium screw anchorage for protraction of mandibular second molars into first molar extraction sites. Am J Orthod Dentofacial Orthop 2008;134:583-91. https:// doi.org/10.1016/j.ajodo.2006.09.055

15. Baik UB. Molar protraction: orthodontic substitution of missing posterior teeth. In: Kim KB, ed. Temporary skeletal anchorage devices: a guide to design and evidence-based solution. BerlinHeidelberg: Springer; 2014:119-60.

16. Jee JH, Ahn HW, Seo KW, Kim SH, Kook YA, Chung KR, et al. En-masse retraction with a preformed nickel-titanium and stainless steel archwire assembly and temporary skeletal anchorage devices without posterior bonding. Korean J Orthod 2014;44:236-45 https://doi.org/10.4041/kjod.2014.44.5.236

17. Nagasaka H, Sugawara J, Kawamura H, Nanda R. "Surgery first" skeletal class III correction using the skeletal anchorage system. J Clin Orthod 2009;43:97-105.

18. Baek SH, Ahn HW, Kwon YH, Choi JY. Surgery-first approach in skeletal class III malocclusion treated with 2-jaw surgery: evaluation of surgical movement and postoperative orthodontic treatment. J Craniofac Surg 2010;21:332-8. https://doi.org/10.1097/ SCS.0b013e3181 cf5fd4

19. Liou EJ, Chen PH, Wang YC, Yu CC, Huang CS, Chen YR. Surgery-first accelerated orthognathic surgery: orthodontic guidelines and setup for model surgery. J Oral Maxillofac Surg 2011;69:77180. https://doi.org/10.1016/j.joms.2010.11.011

20. Yu CC, Chen PH, Liou EJ, Huang CS, Chen YR. A surgery-first approach in surgical-orthodontic treatment of mandibular prognathism--a case report. Chang Gung Med J 2010;33:699-705.

How to cite this article: Baik UB, Kim YJ, Chae HS, Park JU, Julian S, Sugawara J, et al. A new rationale for preservation of the mandibular third molar in orthognathic patients with missing molars. J Korean Assoc Oral Maxillofac Surg 2022;48:63-67. https:// doi.org/10.5125/jkaoms.2022.48.1.63 